\title{
TRATAR A CIDADE COMO ECOSSISTEMA: CONTRIBUIÇÕES TEÓRICA E PRÁTICA VISANDO À SUSTENTABILIDADE URBANA
}

\section{TREATING THE CITY AS ECOSYSTEM: THEORETICAL AND PRACTICAL CONTRIBUTIONS AIMMING URBAN SUSTAINABILITY}

\section{Izes Regina de Oliveira} Arquiteta Doutoranda em Ciências Ambientais - UNESC. Universidade do Extremo Sul Catarinense. Área de estudo: Ecossistema urbano e sustentabilidade. E-mail: izesdeoliveira@hotmail.com

\section{RESUMO}

Este trabalho parte do princípio de que a cidade é um ecossistema e contribui à reflexão do necessário redirecionamento da questão urbana no mundo contemporâneo. Além disso, conceitua ecossistema, traz uma base sobre sistemas e mostra o funcionamento da cidade contemporânea e como seria o funcionamento dela como ciclo metabólico. Analisou-se o paradigma racional como ultrapassado em contraponto da cidade tratada com complexidade, da mesma forma que se apresentaram seus problemas urbanos, apontando alternativas de uma cidade para todos num meio ambiente regenerado para responder aos impactos socioambientais e às mudanças climáticas. Foram buscadas outras práticas urbanas com enfoque numa proposta de mudança de paradigma, assim como proposto reorientar a sociedade e sugerir alternativas para ações na gestão e no planejamento ecossistêmico de forma a tratar a cidade e a arquitetura atreladas ao condicionamento dos ecossistemas de modo a cultivar relações e interações entre a sociedade, o desenvolvimento e o meio ambiente, visando à transição para a sustentabilidade.

Palavras-chave: Ecossistema urbano. Regeneração da cidade. Infraestrutura ecológica

\begin{abstract}
This work assumes that the city is an ecosystem and contributes to the reflection of the necessary redirection of the urban question in the contemporary world. In addition, it conceptualizes the ecosystem, brings a basis on systems and shows the functioning of the contemporary city and how it would function as a metabolic cycle. It was analyzed the rational paradigm as outdated in counterpoint of the city treated with complexity, in the same way that its urban problems were presented, pointing out alternatives of a city for all in a regenerated environment to respond to socio-environmental impacts and climatic changes. Other urban practices focused on a paradigm shift proposal were proposed, as well as proposed to reorient society and suggest alternatives for actions in management and ecosystem planning in order to treat the city and architecture linked to the conditioning of ecosystems in order to cultivate relationships and interactions between society, development and the environment, aiming at the transition to sustainability.
\end{abstract}

Keywords: Urban ecosystem. Regeneration of the city. Ecological infrastructure. 


\section{INTRODUÇÃO}

A perspectiva de alta urbanização prevista para as próximas décadas em função do crescimento demográfico calculado para o Brasil e América Latina, produz uma visão do processo acelerado de impactos. Pelo relatório do "Estado das Cidades da América Latina e Caribe" elaborado pela ONU-HABITAT, a taxa de urbanização no Brasil e nos países do Cone Sul chegará em 2020 a 90\% ONU-BR (2012). Isso supõe grandes demandas para as cidades latino-americanas, o que pode alterar ainda mais a biodiversidade e por pressuposto os serviços ecossistêmicos, os fluxos das águas urbanas e mais impactos socioambientais. A alteração dos serviços ecossistêmicos, a diminuição da biodiversidade e o aumento da miséria e da fome são impactos associados ao objetivo econômico, ao consumismo e ao esgotamento da natureza. Unidos a esses fatos, temas como alteração climática, pegada ecológica, crise hidráulica e urbanização tornam-se contemporâneos e de preocupação recorrente.

De discurso analítico, descritivo e propositivo, o presente trabalho parte do princípio de que a cidade é um ecossistema complexo e sua sustentabilidade está atrelada ao condicionamento dessa complexidade no que diz respeito às relações e interações entre a sociedade, o desenvolvimento e o ambiente. O trabalho propicia a compreensão qualitativa do tema que abrange não só o universo urbano como a biorregião ${ }^{1}$.

Este estudo constrói um conjunto de informações com base teórica nos sistemas complexos que fundamentam a reflexão sobre a forma do crescimento urbano e a percepção da mudança e, assim, repensar e reconduzir o crescimento urbano com abordagem ecossistêmica. Responde ao alerta da urbanização, à (i) mobilidade urbana, à mudança climática, ao esgotamento dos recursos naturais, à miséria e à fome. A tarefa é apresentar propostas para o planejamento urbano e gestão pensados aos moldes da natureza biomimetismo, que possibilite um futuro ambiental e socialmente sustentável.

De acordo com o objetivo apresentado, este artigo está subdividido em três partes: expõe, no primeiro momento, o funcionamento da cidade contemporânea, individualista e consumista cujo movimento linear impacta e polui, e a compara com a proposta de mudança para um metabolismo circular de uma cidade mais eficiente. Na segunda parte, apresenta o pensamento sistêmico com referencial teórico em Capra (2006a; 2006b) e Morin (2001) e ecossistema nos ecologistas Girardet (2010), Odum (2004) e Rueda (2000), assim como nos urbanistas Rogers (2001) e Newman e Jennings (2008), entre outros autores. Na terceira parte

\footnotetext{
${ }^{1}$ Toda a região que comporta os rios, as cadeias de montanhas, os ventos predominantes, as espécies animais e vegetais ali existentes.
} 
deste trabalho, o pensamento dos autores ajudou a fundamentar uma metodologia para buscar o caminho do ecossistema urbano sustentável, através de exemplo prático do planejamento ecossistêmico vivido por 13 cidades do Canadá e outras práticas como propostas para um planejamento integrado, como um todo, social, econômico, ecológico e físico-territorial. Este artigo dá um passo além do estudo iniciado com a obra Sustentabilidade urbana $e$ ecossistema: relações entre a sociedade, o desenvolvimento e o meio ambiente ${ }^{2}$ fazendo comparações com as propostas existentes para o planejamento urbano de cidades sustentáveis. Tendo como pano de fundo a necessidade de outra epistemologia para tratar a cidade.

\section{FUNCIONAMENTO DA CIDADE CONTEMPORÂNEA}

O cotidiano da cidade é repleto de problemas interconectados nas dimensões social, cultural, ecológica, institucional, territorial e econômica, conceituados como complexos porque multidimensionais e interligados. A geração desses conflitos está correlacionada ao modelo de ocupação do solo e à forma desordeira e inconsequente como cresce o ambiente construído cuja tendência é impactar o solo e os fluxos das águas e diminuir a biodiversidade.

Esses problemas são sistêmicos complexos, tratados, porém, de forma linear e fragmentada. Tucci (2008) trata a visão linear do paradigma cartesiano de profissionais da área urbana como arcaica. Isso acresce problemas e suas causas, além disso, aumentam os espaços construídos sem qualidade e faz crescer o setor informal e as áreas ocupadas ilegalmente, produzindo o desequilíbrio social e ecológico e diminuindo a qualidade de vida, resultando em altos custos econômicos, sociais e ambientais.

Esse modelo de soluções pontuais com problemas interdependentes decorre da "metodologia fragmentada" que inicia com a falta de integração entre gestão e planejamento urbano ou da falta total do planejamento, com objetivos, muitas vezes, eleitoreiros. Tal modelo ocasiona conflitos sérios, muitas vezes percebidos ou admitidos pela população depois de decorrido tempo, que resulta, também, em altos custos para recuperar.

Tal abordagem não resolverá nenhuma das nossas dificuldades, limitar-se-á a transferi-las de um lugar para outro na complexa rede de relações sociais e ecológicas. Uma resolução só poderá ser implementada se a estrutura da própria teia for mudada, o que envolverá transformações profundas em nossas instituições sociais, em nossos valores e ideias (CAPRA, 2006a, p. 26).

\footnotetext{
${ }^{2}$ De Oliveira e Milioli (2014)
} 
Os estilos de vida da civilização contemporânea, planetária e globalizada trouxeram problemas socioambientais com todo tipo de destruição dos recursos naturais, culturais e do meio ambiente e desigualdades socioeconômicas, associadas ao objetivo econômico e ao consumismo. A partir da Revolução Industrial, há mais de 250 anos, aglomerações urbanas, da pequena à média e megacidade, com alta ou baixa densidade humana, propiciam expansão urbana, impermeabilizam, degradam terras e a biosfera, acumulam resíduo, apresentam todo tipo de poluição, e, mais recentemente, o efeito estufa altera o clima global.

O progresso econômico, sem dúvida, produziu melhorias consideráveis no que diz respeito ao conforto no nível de vida, oportunidades, progresso, mas remete também ao cenário de riscos de ordem moral, social, de saúde e ecológica. Essa sociedade patriarcal, linear e racional produz más condições de vida e as "doenças do século", violência, estresse, crime, medo, miséria, fome, AIDS, famílias desagregadas, desrespeito às minorias.

Encontramo-nos, assim, numa época de transição, entre o processo de industrialização/urbanização como símbolo de progresso e civilidade e o questionamento da insustentabilidade do desenvolvimento que gera desigualdades no acesso a bens e serviços urbanos e funciona como uma "engrenagem" reproduzindo pobreza e degradação ambiental.

Esses problemas interconectados e interdependentes não encontram solução dos especialistas racionalistas, nas suas áreas de conhecimentos, pois estamos vivendo um grande problema sistêmico por uma racionalidade econômica que marca a crise ambiental determinada pela ciência moderna, mecânica e cartesiana, do modelo unidirecional de acumulação "incompatível a nossa sociedade atual”, cuja essência está na crise de percepção da sociedade (CAPRA, 2006a, p.15). Por sua complexidade, os problemas urbanos são melhor solucionados com base no pensamento sistêmico, muito embora na história das cidades o tratamento dos problemas continue com uma metodologia contrária, em desacordo com sua complexidade e interconexão (JACOBS, 2001; CAPRA 2006a).

Nessa reflexão de problemas interconectados, Girardet (2010) e Odum (2004) identificam o funcionamento da cidade como um processo metabólico linear em que há grande entrada de mercadorias, insumos e energia para se manter e uma saída (Figuras 1, 2 e 3) maior e venenosa de poluição e resíduos em funcionamento independente, fragmentado. 
Figuras 1. 2 e 3 - Processo metabólico linear

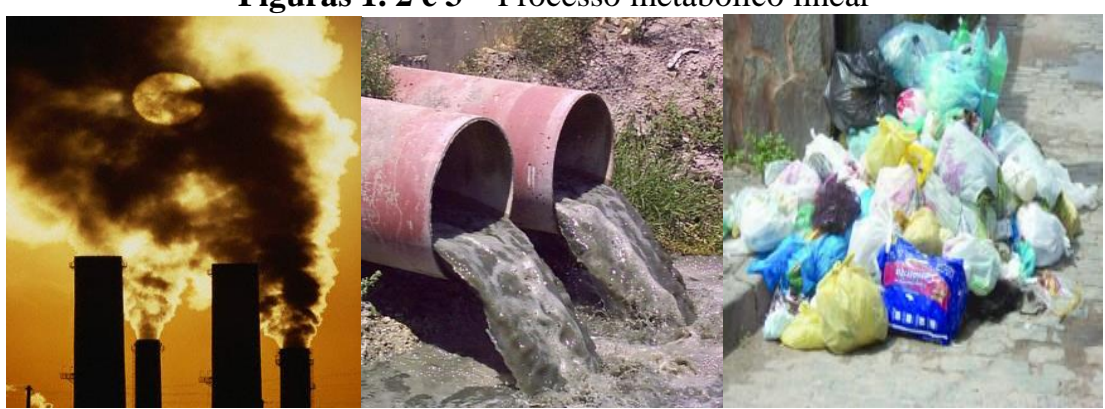

Fonte: (1) http:econsciente-nsp.blogspot.com.br/2009/09/poluicao-industrial.html. Acesso em: ago/2017 (2) https:es.over-blog.com/Residuos_liquidos_claves_para_su_reciclaje-1228321783art381459.html Acesso em : ago/2017. (3) http://jornalmaisnoticias.com.br/sacolinhas-representam-10do-lixo-urbano-brasileiro /. Acesso em: ago/2017.

As cidades são ciclos lineares porque geram resíduos, não se retroalimentam, não introduzem os resíduos no ciclo sistêmico. Essa sociedade de fluxo linear é setorial, especializada e baseada na extração e nos recursos minerais não renováveis (FRANCO, 2000; PESCI, 2004; ROCHA, 2005).

Conceitualmente, o ambiente urbano é um sistema incompleto, porque é alimentador de outro, consome e fornece a estrutura para o fluxo de energia através de outro sistema. Dessa forma, os ambientes de entrada e saída são relativamente muito mais importantes para o sistema urbano (ODUM, 2004). A cidade não capta energia local, busca água longe do local de uso, utiliza energia fóssil, degrada, gera resíduo e polui, necessitando, assim, de contribuições de outros sistemas. Essa característica de fluxo unidimensional de uso e descarte sobrecarrega os sistemas finais de decomposição - poluição, lixo, esgotos. Degrada ecologicamente e perde o equilíbrio como um ecossistema natural. Consumista, é voltada para o conforto dos seus habitantes. Racional e individualista é injusta socialmente.

A visão fragmentada do pensamento abstrato dividiu a sociedade humana em nações, raças e grupos religiosos e políticos, alienando o homem da natureza e, por conseguinte, diminuindo sua humanidade (CAPRA, 2006b, p. 230).

Concluindo, o pensamento mecanicista, além de produzir a especialização e a quantificação, objetivou uma única dimensão, a econômica, incorporou grandes escalas até a planetária e parece desconsiderar o futuro das próximas gerações. Os demais aspectos se transformaram em secundários, embora as necessidades humanas sejam mais complexas, pois o ser completo se expande a todas as dimensões social, cultural, ecológica e espiritual, bem além do econômico. 
A visão racionalista de Newton era a da termodinâmica, cuja $2^{\mathrm{a}}$ lei $^{3}$ afirmava a dissipação não recuperada da energia mecânica, em forma de calor. Ou seja, qualquer sistema físico isolado, ou "fechado", se encaminhará espontaneamente em direção a uma desordem sempre crescente e a entropia continuará aumentando. Essa era uma visão oposta à imagem evolucionista dos biólogos da época, a de um mundo vivo, capaz de ordem e complexidade crescentes. Com a teoria de sistemas, de ordem e desordem, nos sistemas abertos (como as cidades), a entropia pode decrescer e a $2^{\mathrm{a}}$ lei da termodinâmica pode não se aplicar (CAPRA, 2006b).

A cidade contemporânea continua com a visão mecânica e racionalista do final do século XIX, mas a crítica ao sistema consumista da produção capitalista está na ordem do dia. Assim, a transição alcança a ciência e a vida prática para a qual as cidades e seus habitantes precisam capacitar-se para as mudanças de paradigma que incluem estilo de vida, educação, concepção das construções, tipo de crescimento e de cultura.

A partir do século passado, a ecologia emergiu das ciências biológicas para as ciências naturais e sociais (ODUM, 2004). A problemática ambiental abriu um processo de transformação, com novos conhecimentos interdisciplinares e o planejamento intersetorial para gerir o ambiente e o desenvolvimento, de forma sustentável (LEFF, 2004). A ecologia como nova ciência faz interagir o ecossistema, a paisagem, a biorregião, a biosfera e o ser humano com todas as suas dimensões, os quais não podem ser tratados separadamente, porque fazem parte de um sistema complexo.

\section{DO METABOLISMO LINEAR AO CIRCULAR}

A natureza funciona com metabolismo circular, por isso não produz resíduo e usa a energia do sol como alimento. Odum (1988) e Girardet (2010) afirmam a necessidade de incluir os extensos ambientes de entrada e saída para uma cidade poder ser considerada um ecossistema no sentido completo. Dessa forma, ao reciclar resíduos e recursos e ao se utilizar de energia renovável, a cidade propõe um metabolismo circular e fica mais autotrófica ${ }^{4}$ porque se sustenta no próprio ecossistema.

\footnotetext{
${ }^{3} 2^{\mathrm{a}}$ Lei: A todo fluxo de energia deve estar associado um fluxo de calor no qual desaparece a energia que não está disponível para os sistemas: a entropia de qualquer processo real aumenta sempre; a noção de entropia mais conhecida é a de deterioração (PILLET, 1993: 144).

${ }^{4}$ Autotrófico é um sistema autoalimentador, é o ecossistema que produz energia interna suficiente para atender às necessidades de respiração através das ações autotróficas. O aproveitamento da fonte de energia solar regular aumenta a chance de sustentabilidade (ODUM, 1988, p. 11). Os sistemas autotróficos utilizam os elementos abióticos minerais para produzir matéria orgânica e garantir a vida através da absorção da energia solar, por complexos processos metabólicos (CAPRA, 2006b)
} 
Figura 4 e 5 - Metabolismo linear e metabolismo circular
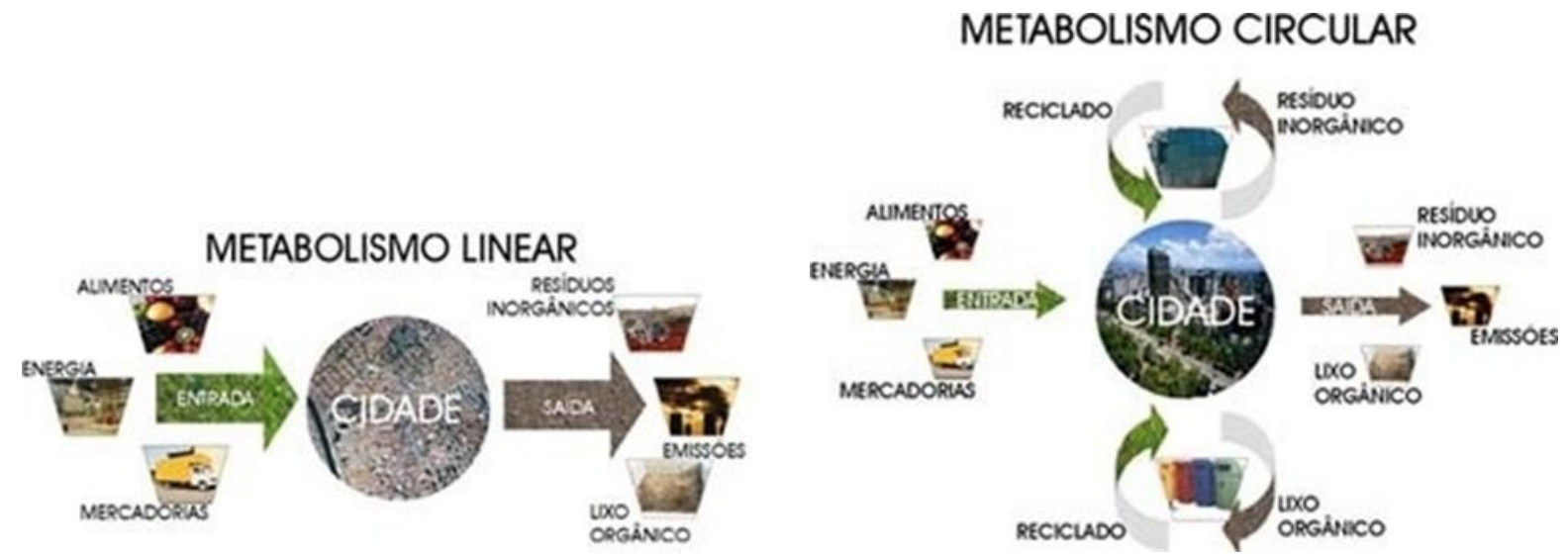

Fonte: http://www.vitruvius.com.br/revistas/read/arquitextos/05.059/472 Acesso: Julho 2018.

\section{COMPARANDO OS DOIS METABOLISMOS}

A cidade contemporânea funciona com metabolismo linear (Figura 4) porque consome e polui em alto grau com entrada de combustíveis fósseis como carvão e petróleo, alimentos e mercadorias que se metabolizam linearmente produzindo resíduo orgânico e inorgânico, líquidos e sólidos, e emitem gases.

A proposta da cidade com metabolismo circular (Figura 5) é minimizar novas entradas de energia, alimentos e materiais, maximizando a recuperação e reutilização do resíduo inorgânico e reciclagem do orgânico, recuperando águas servidas e captando águas pluviais; reduzir o consumo e o descarte, insistir no consumo dos recursos renováveis; conservar ou baixar o consumo dos recursos não renováveis; maximizar a reutilização dos recursos orgânicos e inorgânicos (GIRARDET, 2010) Dessa forma, diminui-se a entropia, e a segunda lei da termodinâmica pode não funcionar.

Essas ações objetivam a circularidade de uso e reutilização que aumenta a eficiência global do núcleo urbano e reduz o impacto no meio ambiente, em substituição aos atuais processos lineares de poluição e degradação. Trazendo as necessidades de consumo mais perto do ponto de produção, restabelece o gabarito humano, a capacidade do ecossistema e o equilíbrio ecológico. Fontes local e renovável de energia solar, eólica, ou biocombustível, além de reduzirem o consumo energético, desvinculam o local da dependência energética externa. Ou seja, produzindo a energia necessária, localmente, tira a dependência de formas de energia que venham de fora, seja através de fios ou canalizações, seja através de transporte rodoviário de outros locais e até outros países. As fontes que mais predominam são combustíveis fósseis que causam GEE gases de efeito estufa. A necessidade de reduzir essa 
dependência e a vulnerabilidade à escassez se encontra na mudança da forma da energia e na atitude das ações.

Com outras tecnologias sustentáveis que caibam na capacidade do bioma, as cidades poderão adquirir características mais autotróficas: a eficiência energética, acima citada, através da energia solar passiva e outras fontes, local e biorregional; as necessidades básicas de alimento produzidas dentro da biorregião; o design e arquitetura ecológicos como o uso de terra crua para fechamento de paredes, o telhado verde, materiais reciclados e recicláveis e a água captada e esgotada no local.

Na proposta de Herbert Girardet (2010), uma cidade, ao minimizar novas entradas de energia e materiais e maximizar a reciclagem e a reutilização, transformará seus fluxos para um metabolismo circular se transformando num ecossistema completo. A cidade sustentável é a que está em equilíbrio com sua paisagem e vive do lucro líquido ecológico da sua região de apoio (BERRY 2001 apud NEWMAN; JENNINGS, 2008). Ou seja, a abrangência das suas necessidades de consumo e descarte deve estar dentro dos seus limites biorregionais. Só assim estará trabalhando dentro das suas dimensões sustentáveis. Para se transformar num ecossistema urbano sustentável, deverá, ainda, reconhecer a natureza como parte do sistema e atender às necessidades socioculturais da população. Este seria um conceito de "pegada ecológica" ou seja, podemos usar somente a natureza que temos na nossa biorregião. Além desse consumo, estaremos degradando.

Concluindo esta primeira parte do trabalho, vimos que, ao modelar a cidade aos ecossistemas naturais, supõe-se que ela produza na sua biorregião, fixe energia primária, não gere resíduos tampouco sobrecarregue seus sistemas de decomposição, tenha características de metabolismo circular, e envolva diretamente a população na consolidação da qualidade de vida.

\section{COMPREENDER SISTEMA PARA ABORDAR O ECOSSISTEMA}

Desde 2001, a UNESCO, através do programa MaB - Man and Biosphere (Homem e Biosfera), considera a cidade um sistema ecológico, porque percebe vitais as necessidades humanas sobre os serviços dos ecossistemas o que nos tornam dependentes da saúde desses. Essa relação de dependência incide sobre os serviços do ecossistema: temperatura, pluviometria, natureza do solo, presença de água e recursos. Por isso, a biodiversidade é base

\footnotetext{
${ }^{5}$ Pegada ecológica é a área de terra produtiva e de ecossistemas aquáticos necessários para produzir os recursos utilizados e absorver os resíduos produzidos por uma determinada população com um padrão de vida específico, onde quer que essa área esteja localizada. UNEP

https://www.unep.org/geo/sites/unep.org.geo/files/documents/cap2_areasurbanas.pdf.
} 
para a vida no planeta, para a produção do ar, proteção e regulagem da quantidade e qualidade de água, umidificação da atmosfera, estabilização das margens de rios e encostas, abrigo para fauna e a presença da flora. Não por acaso, o planejamento urbano ecossistêmico, como veremos adiante, engloba sistemas naturais ecológicos integrados ao contexto sociocultural da cidade.

Está confirmada a relação dialética de dependência/independência para interagir com o meio que Morin (1984), Capra (2006b) e Odum (2004) informam, visto que somos seres essencialmente ambientais e fatalmente precisamos dos serviços ecossistêmicos. Esses são benefícios da natureza que ganhamos para reverenciá-la, perceber a beleza da paisagem, da água limpa para beber, do ar para respirar, do alimento para sobreviver, da roupa para agasalhar. O contrário dos benefícios é impactar com a perda da biodiversidade, riscos climáticos e economia obsoleta.

Sistêmico e ecológico são sinônimos ODUM (2004). O fenômeno sistema é a interação entre o todo e as partes numa organização constitutiva indissolúvel. É evidente em tudo e não trata dos temas separadamente, supondo aplicar o conhecimento ecológico nas tecnologias, nas estruturas e nas instituições, necessário ao estado de inter-relação e interdependência de todos os fenômenos físicos, biológicos, psicológicos, sociais e culturais (MORIN, 1984; 2001; CAPRA, 2002). Ao se aplicar em todos os campos de estudo, transcende as fronteiras disciplinares; abrange a cidade como um todo transdisciplinar.

O meio urbano é um sistema mutável e está intimamente interligado ente as diversas dimensões ao ecossistema mundo, numa relação dialética de dependência/independência. Mas, a cidade continua fundamentada no modelo que pouco interage com os indivíduos e seus contextos.

O todo sistêmico da cidade está relacionada à simbiose com seus biomas. A interdependência que o ser humano e a cidade têm com a natureza é comparada por Odum (1988) com os níveis de sistemas dentro da ecologia, da mesma forma que um órgão não poderia sobreviver durante muito tempo como unidade, sem o seu organismo.

O fenômeno sistema evidencia a necessidade que o ser humano tem dessa relação com a natureza, necessária para o bem-estar humano e a qualidade de vida. O equívoco da sociedade ocidental e racionalista está na distância do ser humano e da cidade com a natureza, ao tentar dominar, através da técnica e da ciência, os animais, plantas, terras, águas e outros homens.

A teoria sistêmica enfatiza as relações de forma dinâmica. Esse é outro modo de pensar, em termos de conexões, relações e contexto. Mas a característica mais geral é a visão 
das partes para o todo, como veremos adiante. Rueda (2000), coloca as pessoas e a cidade como ecossistemas interdependentes de outros sistemas de informações, matérias e energias que estruturam o sistema cidade cujos entornos se modificam em consequência dessa interrelação. Estes não necessariamente deveriam causar impactos ambientais.

Percebe-se a interconexão entre os problemas sociais e culturais do mundo com os problemas do meio ambiente e da economia, que, por sua vez, estão diretamente interligados aos problemas de energia, aquecimento global, mudanças climáticas, (in) segurança, miséria, doenças, analfabetismo. Confirma-se a teoria de Capra (2006b) de que, para entender o todo, deve se entender as interconexões de suas partes.

\section{CARACTERÍSTICAS-CHAVE DA TEORIA SISTÊMICA}

Para compreender os ecossistemas e a natureza, Capra (2006b) resume as características-chave do pensamento sistêmico: a mudança das partes para o todo, níveis de sistemas e redes de relações. "[...] não há partes, em absoluto” (2006b, p. 47). Entende-se que as partes de uma cidade, como os bairros, o trânsito, o sistema viário, sistema de água e esgoto, as estruturas edilícias habitacionais, educacionais, de saúde e a sociedade, só podem ser entendidas no contexto da própria cidade como um todo, considerando o seu meio ambiente, pois, segundo Capra (2006b, p. 46), "as propriedades das partes não são propriedades intrínsecas". Essas propriedades "são destruídas quando o sistema é dissecado" em elementos isolados, uma vez que o todo é sempre diferente da mera soma das partes.

Sistemas aninhados dentro de sistemas encontrados em níveis sistêmicos do mundo vivo é outro critério-chave do pensamento sistêmico. Cada nível exibe propriedades diferentes denominadas “emergentes”, uma vez que emerge nesse nível em particular (CAPRA, 2006b).

O autor descreve o conceito de estresse como o desequilíbrio de um organismo que pode ser compatível com a visão sistêmica da cidade. O nível sistêmico população poderá ter como estresse a alta densidade; no nível extensão, crescimento, o estresse pode ser a expansão urbana; no nível impermeabilização, o estresse pode ser as enchentes; aplicando os mesmos conceitos a diferentes níveis sistêmicos poderão ter níveis de diferentes complexidades.

A mudança das partes para o todo surge das relações de organização das partes. Essa organização tem um padrão, chamado autopoiese - característica que define a vida, ou “autocriação", num padrão de rede, no qual a transformação dos outros componentes da rede adquire capacidade de autor-regulação, de auto-organização. A capacidade regenerativa que os seres vivos têm de renovar e reciclar seus componentes são os processos de aprendizagem, adaptabilidade, desenvolvimento e evolução (CAPRA, 2006a; 2006b). As adaptabilidades da 
cidade contemporânea como necessidade de reciclar o lixo, buscar alternativa energética, fazer um design sustentável, os novos meios de mobilidade urbana (calçadão/bicicleta/trem) são exemplos de capacidades regenerativa da cidade e de adaptabilidade às novas necessidades. Estas são as emergências do paradigma sistêmico, que aqui colocamos como exemplos de novos padrões de organização para uma cidade mais sustentável. Na teoria sistêmica, este conceito é caracterizado como autopoiese, ou seja, "autocriação", autorregularização.

\section{O PENSAMENTO ECOSSISTÊMICO EMPREGA CONCEITOS EPISTEMOLÓGICOS DA TEORIA SISTÊMICA \\ Princípios básicos da ecologia citados por Capra:}

a) interdependência: a dependência mútua de todos os processos vitais dos organismos faz uma comunidade humana sustentável e consciente das múltiplas relações entre seus membros. O comportamento de um elemento depende do comportamento de muitos outros;

b) reciclagem: o fluxo cíclico dos recursos fez as comunidades de organismos evoluírem ao longo de bilhões de anos, usando e reciclando continuamente as mesmas moléculas de minerais, águas e ar;

c) Parceria: no ecossistema urbano sustentável as transformações da energia e recursos devem circular em ciclos metabólicos em cooperação para estabelecer ligações. O que sobra de uma produção deve ser matéria prima de outra, em parceria e cooperação. Tudo deve ser reutilizado ou reciclado (2006b, p. 231-235).

Essa é apenas uma parte da sustentabilidade urbana, pois tratar a cidade como um ecossistema urbano é concebê-la como organização das unidades complexas é não reduzi-la em unidades, nas quais todos os setores têm a mesma importância.

Um ecossistema natural é constituído por um espaço ocupado pelo agrupamento dos seres vivos, suporte material, inorgânico e nutritivo; por um fluxo solar, fonte de toda a energia; por organismos que lá vivem; e por uma reciclagem de matéria. Suas características, de modo geral, são o processo próprio de produção, respiração, trocas gasosas, um fluxo solar e reciclagem. O essencial de um ecossistema é a produção e consumo num ciclo de reciclagem aberto à energia solar, assim como fluxos de matérias orgânicas, nutrientes, gás carbônico e oxigênio que determinam seu crescimento. $\mathrm{Na}$ natureza, os resíduos são produzidos por organismos vivos (plantas, animais e humanos), os quais incluem materiais fecais, restos de comida e biomassa morta. O ecossistema produz biomassa, ou massa total de 
matéria vegetal e animal, viva ou morta. Assim, a construção da biomassa pela fotossíntese, a reciclagem de resíduos em nutrientes, definem a maior diversidade dos ecossistemas terrestres (PILLET, 1993, p. 138-162).

Um ecossistema é um ambiente biológico que inclui organismos vivos (bióticos) vegetais, animais, bactérias e fungos - e organismos não vivos (abióticos) - água e minerais , que inseparavelmente interagem entre si e com o ambiente físico, numa dada área, num determinado tempo, de tal forma que a energia solar produz estruturas bióticas claramente definidas e uma ciclagem ou troca de materiais entre as partes vivas e não vivas. $\mathrm{O}$ ecossistema é composto por: um ambiente de entrada - AE, com formas de energia (solar, ventos, água) que fazem circular os materiais e organismos dentro de um sistema - $S$, delimitado, que formam um ambiente de saída AS com suas energias processadas e emigração de organismos: $\mathrm{AE}+\mathrm{S}+\mathrm{AS}=$ ecossistema (ODUM, 2004).

A Avaliação Ecossistêmica do Milênio - AM (2001-2005) define ecossistema como um complexo dinâmico de comunidades vegetais, animais e microrganismos no seu meio, interagindo como uma unidade funcional. Além disso, aborda todo o leque de ecossistemas, inclusive os intensamente administrados e modificados pelo homem, como regiões agrícolas e urbanas. A intenção da AM é avaliar as consequências das mudanças nos ecossistemas sobre o bem-estar humano, estabelecer uma base científica para fundamentar as ações necessárias e assegurar a conservação e suas contribuições para o bem-estar humano.

O ecossistema é um fenômeno de integração natural entre vegetais, animais e humanos com caráter auto-organizado e organizacional em combinação de relação de espécies diferentes, donde resulta uma espécie de ser vivo que é o próprio ecossistema. Esse "ser vivo" é muito robusto porque se reorganiza e evolui e, ao mesmo tempo, muito frágil, podendo morrer se injetarem nele veneno químico em doses que provoquem a morte em cadeia de espécies ligadas umas às outras e se alterarem as condições elementares da vida. Portanto, degradar o ecossistema é degradar o próprio homem, que, por ser um sistema aberto, precisa se alimentar de energia, de ordem e complexidade (MORIN, 1984, p. 25).

A cidade pode ser considerada um ecossistema como qualquer outro, por ser composta com elementos bióticos e abióticos num espaço delimitado onde os seres humanos interagem com esses elementos. Há componentes novos como edifícios, transportes, infraestruturas de água e esgotos, parques esportivos, plantas introduzidas e animais, que interagem em um sistema (NEWMAN; JENNINGS, 2008: 93; REGISTER 2008).

A teoria dos sistemas vivos poderá unir comunidades ecológicas e humanas e transformar as cidades com mudança de paradigma, no qual pensamentos, atitudes, educação 
e ações reconhecem a natureza como parte do sistema. Ou seja, no paradigma cartesiano, o antropocentrismo, o homem é o centro de tudo. No paradigma ecológico a natureza é o contexto onde os seres vivos estão inseridos. No pensamento do ecólogo naturalista Salvador Rueda (2001) ao reconhecermos a natureza como parte do sistema, esta não será mais exterior tampouco o ser humano o centro. Ela passa de exterior a ser o centro e o humano, apenas parte do sistema.

\section{CAMINHO PARA UM ECOSSISTEMA URBANO SUSTENTÁVEL}

\section{O PLANEJAMENTO ECOSSISTÊMICO}

Na década de 1991, treze cidades canadenses, entre elas Vancouver, Montreal e Saskatoon, aplicaram princípios ecossistêmicos nos planos de uso do solo. Foi a primeira geração de ordenamento a aplicar esse tipo de abordagem que reabilitou e renovou cidades, levando a sério os impactos sociais, econômicos, biofísicos e respeito pelas complexidades ecológicas, limites e incertezas. Essas treze cidades testaram na prática uma possibilidade real em que os projetos propuseram nova forma da relação humano/natureza e objetivos ecológicos interdependentes, confirmando que essa relação tem implicação no plano de uso do solo e na utilização do espaço urbano.

A abordagem ecossistêmica foi levada a sério, e o bem-estar ecológico foi considerado como base essencial. Isso resultou em ganhos econômicos e sociais para as comunidades. Esse planejamento, fundamentado nos princípios ecossistêmicos, dá ênfase à fixação de metas de longo prazo, atenção aos efeitos das decisões e favorece mecanismos suficientemente flexíveis para responder aos problemas e oportunidades imprevistas (GIBSON et al., 1997). Hoje, essas treze cidades estão no ranking das mais "verdes" do mundo.

Tensões entre objetivos econômicos e ecológicos podem surgir, sendo necessário equilíbrio contínuo entre tensões e perturbações externas para as comunidades se adaptarem às condições mutáveis (CAPRA, 2006b).

Os autores canadenses fizeram um feedback comparando um plano tradicional que usa sistemas lineares à proposta ecossistêmica. Nessa proposta, a atividade humana é parte do ambiente e do limite de recursos disponíveis, e há respeito à resiliência ecossistêmica, metas de saúde e integridade dos ecossistemas, interconectados aos objetivos sociais, econômicos e políticos, reconhecendo a interdependência mútua. 
Montamos o Quadro 1, resumindo os sete princípios que regem o planejamento canadense de Gibson et al (1997), comparando o planejamento convencional em (A) e a abordagem ecossistêmica em (B):

Quadro 1 - Princípios do planejamento urbano: "A" convencional e "B" ecossistêmico $\mathbf{1}^{\mathbf{0}}$ Princípio: limites naturais para unidades de base do planejamento

$A$. Raramente reconhece os fatores ecológicos.

$B$. Respeita as funções ecológicas, seguindo fronteiras naturais (no Brasil: biorregião, regime hídrico, zoneamento ecológico-econômico; Áreas de Preservação Ambiental (APA); e Áreas de Relevante Interesse Ecológico (ARIE)).

$2^{\mathbf{0}}$ Princípio: desenho com a natureza

A. Manipula a terra ao serviço do capital. Substitui o complexo ecológico pela produção técnica sob os preceitos dos sistemas lineares.

$B$. A atividade humana é parte do ambiente e do limite de recursos disponíveis, em que a resiliência ecossistêmica é respeitada, sob os ciclos dos recursos do sistema natural e do desenho biológico.

$\mathbf{3}^{\mathbf{0}}$ Princípio: consideração global e efeitos cumulativos

A. Presunção dos negócios sobre o sistema com planificação em curto prazo.

$B$. Adota perspectiva ampla, até as próximas gerações com efeitos cumulativos, em que o sucesso local será assegurado além fronteira, com melhorias em níveis regionais e globais.

$\mathbf{4}^{\mathbf{0}}$ Principio: incentivar a tomada de decisões interjurisdicional

$A$. Planejamento e gestão são distintos e as autoridades agem isoladamente.

$B$. Tenta superar essa fragmentação encorajando novas unidades de planejamento, agências e métodos que promovam integração interjurisdicional de tomada de decisão.

$\mathbf{5}^{\circ}$ Princípio: assegurar a consulta e facilitar a cooperação e parceria

A. A participação pública, quando existe, é obrigação legal e meramente formal.

$B$. Ativamente, pretende envolver o maior leque de partes interessadas, de forma eficaz e transparente, no processo de planejamento.

$\mathbf{6}^{\mathbf{0}}$ Princípio: acompanhamento de longo prazo, "feedback" e adaptação dos planos

A. Poucos recursos são utilizados no uso dos solos e planejamento ambiental, para avaliar o que acontece nas comunidades e ecossistemas.

$B$. Exercício de aprendizagem social, processo cíclico e interativo sem respostas definitivas com revisão e mecanismos de acompanhamento, fazem as comunidades avaliarem os progressos na implementação dos planos e adaptação às novas condições.

$\mathbf{7}^{\mathbf{0}}$ Princípio: adotar uma abordagem interdisciplinar à informação.

$A$. Informações sociais, demográficas e econômicas têm sido enfatizadas com poucas tentativas para avaliar a capacidade ecológica ou para avaliar como a satisfação das demandas socioeconômicas pode afetar as funções ecológicas.

$B$. Implica uma maior cooperação entre os provedores de informações, tanto da população como técnicas. Reconhece que informação não elimina incertezas no planejamento e que só podem tornar-se disponíveis com o desdobramento do plano.

\section{Fonte: Quadro montado pela autora ${ }^{6}$}

\footnotetext{
${ }^{6}$ Citado em De Oliveira e Milioli (2014)
} 
Pelo estudo, já percebemos que, para o ecossistema urbano ser sustentável, deve reconhecer a natureza como parte do sistema, além de atender às necessidades socioculturais da população. Da mesma forma, após a revisão dos planos canadenses, foram acrescentados mais três princípios complementares, todos buscando equilíbrio com as necessidades sociais e culturais e compromisso democrático, como a seguir citado.

Quadro 2. Feed back dos planos canadenses

a) Encontrar equilíbrio ecológico, social e econômico, reconhecer que estão relacionados e devem ser exercidos em conjunto.

b) Valorizar a comunidade com compromisso de lugar, integrando objetivos ecológico, social e econômico ao ordenamento territorial. Isto requer mudanças nas atitudes, nas estruturas institucionais, e comportamentais que não podem ser impostas.

c) Envolver aspectos da mudança democrática, aprendizagem social, comunidade e arquitetura ecológica.

\section{Fonte: Quadro montado pela autora}

O planejamento ecossistêmico leva a sério os impactos sociais, econômicos e biofísicos para os quais não existem corretivos fáceis ou compensações adequadas, bem como reconhece o crescimento através da resiliência ${ }^{7}$ das comunidades e dos ecossistemas. O planejamento convencional repousa sobre uma fé no crescimento em que a técnica "resolve tudo". A mensagem é clara: é necessária outra maneira de abordar os problemas urbanos que deverá ser integrada, de forma mais eficiente, mais sensível à ecologia e à comunidade, mais respeitadora das incertezas e aberta ao cidadão, envolvendo o que prevaleceu nesses planos canadenses: a abordagem ecossistêmica das cidades.

\section{PRÁTICAS PARA RECUPERAR O ECOSSISTEMA E RENOVAR A CIDADE NAS SUAS DIMENSÕES COMO UM TODO PARA FINS DA TRANSIÇÃO PARA A SUSTENTABILIDADE}

"Na natureza nada se cria, nada se perde, tudo se transforma" Lavoisier

A perspectiva da cidade como ecossistema sustentável dá um passo adiante aos desafios urbanos ao reconhecer a necessidade de imitarem padrões e processos dos sistemas naturais, a importância da biodiversidade e a participação da sociedade (NEWMAN; JENNINGS, 2008; ROGERS, 2001). Vale dizer que o "debate pela sustentabilidade é uma batalha conceitual” (LEFF, 2010, p. 45). Esse ponto de vista coloca os humanos como parte do sistema socioecológico cujo foco está nas relações e processos que suportam a vida em

\footnotetext{
7 A resiliência pode ser aplicada às cidades. Elas também precisam continuar a responder pelas crises e se adaptar a formas de mudança e crescimento diferenciado. As cidades necessitam tanto de um interior vigoroso e soluções boas, quanto estruturas físicas fortes, para construir o desenvolvimento. In: NEWMAN, Peter. Resiliente cities: responding to peak oil and climate change. Island press: Washintong, 2009.
} 
suas inúmeras formas, especialmente as parcerias e cooperações (NEWMAN et al., 2008; CAPRA, 2002b). Entende que os caminhos para construir a sustentabilidade implicam não somente uma mudança de racionalidade social e produtiva, como também uma pluralidade de racionalidades culturais de base ecológica sustentada por projeto democrático com justiça ambiental (LEFF, 2010, p. 45-53). Essa é a mudança para o paradigma sistêmico, é a forma com que Newman e Jennings (2008), Capra (2006b), Register (2006), a permacultura de Mollison (1994), as ecovilas e as políticas públicas para um planejamento integrado do desenvolvimento, a seguir proposto, sugerem construir comunidades humanas sustentáveis, baseadas no entendimento dos ecossistemas naturais.

As práticas para recuperar o ecossistema e renovar a cidade em todas as suas dimensões social, econômica, ecológica, cultural e infraestrutural, como um todo ecossistêmico, para fins de transição para a sustentabilidade, foi baseada na pesquisa da autora para a realidade das cidades latino-americanas. Esses princípios ecossistêmicos e relações socioecológicas formam um conjunto de aspirações desenvolvidas num workshop organizado pela UNEP (United Nations Environment Program) sobre Construção dos Ecossistemas Urbanos. O PNUMA (Programa das Nações Unidas para o Ambiente) produziu em Melbourne - Austrália os Dez Princípios de Melbourne para as Cidades Sustentáveis (PNUMA, 2002). Dentre os Dez Princípios de Melbourne, o quinto é o núcleo da teoria dos sistemas, o qual modela as cidades como um ecossistema sustentável.

\section{SUGESTÃO DE POLÍTICAS PÚBLICAS E AÇÕES PARA UM PLANEJAMENTO INTEGRADO DO DESENVOLVIMENTO:}

1. Redes interconectadas: todos os membros de uma comunidade ecológica estão interligados numa vasta e intrincada rede de relações (CAPRA, 2006b). Resgatar a cultura dos povos é importante para compreender a essência da existência, aguçar a participação, o prazer, a arte, a revolta e a contestação, revelar a organização, a estruturação, a programação social e tudo que é propriamente humano. Histórias, cerimoniais e rituais são práticas que ligam as pessoas aos seus lugares, fortalecem a relação do homem com o mundo e demonstram a importância do papel da cultura. Uma política cultural constituída de novas humanidades será útil para enfrentar essa crise, que não é ecológica, apenas; é das humanidades, social e econômica (MORIN, 1984, p. 266-69). Bairros “caminháveis”, espaços para pedestres e ciclovias são a proposta defendida pelos urbanistas Register (2006), Rogers (2001) e Rueda (2000) para facilitar interações e práticas conectivas. 
2. Incentivos fiscais para técnicas amenas: o princípio do desenho ecológico é dar visibilidade a um mundo mais humano e aos processos ecológicos para alimentar as conexões dessas consequências, despertando a apreciação ecológica para os fluxos de energia e aos materiais que apoiam a vida no planeta (NEWMAN; JENINGS, 2008). Essas ações que minimizam a poluição e referenciam a estética do lugar melhoram a qualidade de vida e controlam a erosão: viabilizar a introdução dos recursos de água, ar, solo, subsolo, vento, floresta e vegetação como componentes de planejamento urbano; dar incentivos fiscais; e promover o conhecimento e estudo de técnicas amenas para as formas ecológicas dos fluxos de água, energia e materiais.

3. Diversidade cultural, econômica e ecológica: o saber ambiental fundamenta o modelo de ecossistema urbano sustentável com objeto econômico interdisciplinar cuja produção deve ser redefinida e fundamentada entre os potenciais ecológicos, a produtividade tecnológica e a criatividade cultural. Uma economia com valores culturais. No dizer de Leff (2010) a cultura de cada comunidade dá significado aos seus saberes, seus conhecimentos e à sua natureza aumentando o fluxo de possibilidades para si.

4. Parques, bosques e corredores ligados entre si, podem formar uma rede de diversidade ecológica numa cidade, A proposta é criar programas e estratégias com o objetivo de fomentar uma rede que responderia como reserva suficiente para aumentar a biodiversidade do município e região. Essa rede ajudaria na saúde dos ecossistemas e manteria os serviços vitais que os ecossistemas nos propõe, como suprir necessidades de quantidade e qualidade de água e alimentos, entre outros serviços (MOLLISON; SLAY, 1994, p. 193; NEWMAN et al., 2008, p. 114). Outra rede ecológica é formada pelo grupo industrial "ZERI” (Zero Emissions Research and Initiatives) zero resíduo e zero desperdício. Este exemplo ecológico incorpora estratégias ecossistêmicas de tecnologias limpas, transporte local, recuperação de materiais e culturas tradicionais, assim como desenvolve redes descentralizadas e abordagens cooperativas (CAPRA, 2006b). Não há resíduo: o subproduto de uma empresa é o recurso de outra, dentro da biorregião. Respondem em maximização de lucro e produtividade e redução de impactos ambientais e culturais.

5. A escala humana na economia local e biorregional de sustento: a escala está cada vez mais importante, e o critério é restabelecer o gabarito humano e a capacidade do bioma para a prestação dos recursos. Por isso, as necessidades básicas de 
consumo, para a sobrevivência humana de alimentos, água e energia, devem ser cumpridas mais perto do ponto de produção (CAPRA, 2006b; NEWMAN; JENNINGS, 2008). A proposta é um plano de desenvolvimento econômico para incentivar a produção alimentar orgânica local e biorregião. Exemplos em funcionamento são as Brooklyn Granges ${ }^{8}$ - no Brooklyn, Nova Yorque. Estados Unidos, e outras n o Canadá. Herzog (2013) cita a amplitude deste exemplo em Cuba. Este país deu incentivo governamental e transformou o sistema convencional em cultivo local. Emprega no setor, 200 mil pessoas e oferta $40 \%$ do consumo de frutas e vegetais.

6. Energia solar e arquitetura ecológica: atividades ligadas à construção civil consomem cerca de metade da energia produzida, em materiais e transporte e na energia gasta no conforto da vida. $\mathrm{O}$ conceito de bioarquitetura, também denominada ecoarquitetura, concebe o projeto ecológico com o argumento de reduzir a emissão de GEE gases de efeito estufa. Usa técnicas limpas e baratas e materiais disponíveis localmente como formas passivas de eficiência energética. Neste tipo de projeto arquitetônico as temperaturas são confortáveis e a água é quente sem o uso da eletricidade. A luz é abrangente através da ventilação passiva. Este tipo de arquitetura usa materiais reciclados e recicláveis; design sustentável para captação de água, tratamento de águas residuais e escoamento da água da chuva, no local.

A proposta são prazos legais para forçar a produção de edificações energeticamente eficientes, como fazem diversos países desenvolvidos e incentivo fiscal para a bioarquitetura em geral.

7. Incorporar a natureza na cidade: a cidade e os indivíduos agem e retroagem em seu ambiente com "uma identidade própria e uma identidade de dependência ecológica que os liga a seu ambiente" (MORIN, 2003, p.253). Por isso, os ecossistemas urbanos devem ser saudáveis, sem resíduos, autorreguláveis, autorrenováveis, resilientes e flexíveis, como qualquer ecossistema natural. A proposta é trabalhar o planejamento urbano usando os fluxos da água como nos exemplos de transformação a partir da renaturalização de córregos e rios, despoluição por biorremediação (Figura 3), prevenção de enchentes com

\footnotetext{
88 mil m² de produção orgânica sobre lajes, nos bairros Brooklyn e Queens de NY - USA, fornecem frutas e vegetais para restaurantes e feiras locais, desde 2010, e ainda aulas e oficinas de educação ambiental (HERZOG, 2013).
} 
reintrodução da biodiversidade, infiltração e retardamento das águas, como os jardins de chuva, telhados jardins, pavimentação permeável. A permacultura reutiliza águas residuais em canais sistêmicos para reter e deter águas superficiais e prevenir enchentes ${ }^{9}$.

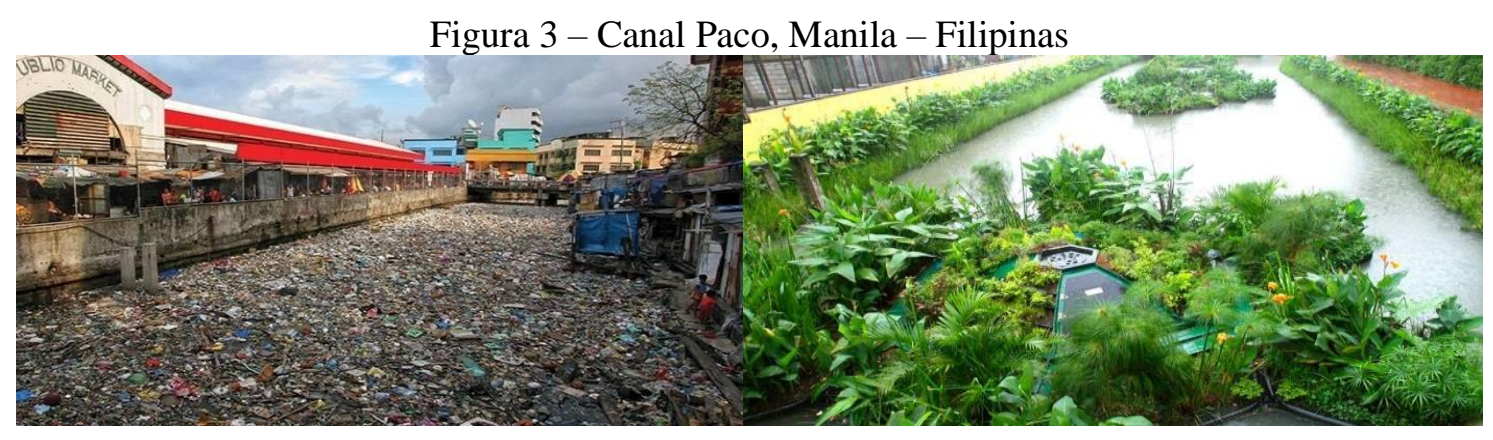

Fonte: https://super.abril.com.br/blog/planeta/sistema-de-tratamento-ecologico-recupera-riospoluidos-e-cria-jardins-flutuantes. Acesso: Ago, 2017.

8. Mudança de hierarquias para redes: o paradigma ecológico inclui "uma mudança na organização social, uma mudança de hierarquias para redes". Os governos centralizados não são capazes de atuar localmente nem pensar globalmente. A ética planetária e as novas formas de organização do paradigma ecológico incluem uma mudança na organização social de hierarquias para redes (CAPRA, 2006b p. 28). Capacitar e mobilizar pessoas que conhecem os recursos locais para participarem nas comunidades supõe-se envolverem nas decisões que as afetam. Na ecovila, a governança é circular, com empoderamento das pessoas, pelas decisões por consenso. São métodos indígenas de "aprender fazendo" para aumentar a resiliência dos sistemas sociais.

9. A renovação urbana: o critério das dimensões deve ser a escala humana no que diz respeito a estruturas, organizações e empresas. Renovar a cidade à pequena escala equivale à regeneração que os ecossistemas naturais usam quando há perturbação (CAPRA, 2006b). Priorizar o pedestre, fomentar o ciclismo como locomoção, diminuir as dimensões e conter as expansões é foco da cidade compacta que se transforma em várias comunidades menores com recentralização física, restaura espaços públicos e trabalha para os processos ecológicos se tornarem viáveis novamente, copiando os ecossistemas, trazendo mais vida à cidade (REGISTER,

\footnotetext{
${ }^{9}$ Village Homes - Davis. Califórnia tem processos de drenagem e direcionamento das águas superficiais, $90 \%$ reutilizadas, através de sistema natural que repõe o suprimento subterrâneo em valas e canais por onde escorrem, ladeadas por árvores e arbustos, recompondo a natureza do ecossistema aquático, biológico e animal, resultando em economia (MOLLISON; SLAY, 1994).
} 
2006; NEWMAN, 2002; ROGERS, 2001; RUEDA, 2000). As novas propostas de regeneração de espaços urbanos estão tratando a cidade dentro do conceito de resiliência. Buscam a escala do bairro de maneira que os habitantes percorram pequenas distancias à pé e bicicleta ou usem transportes de massa.

Figura 4 - Rio Cheonggyecheon - Seul, Coreia do Sul. Restauração biológica aquática e urbana

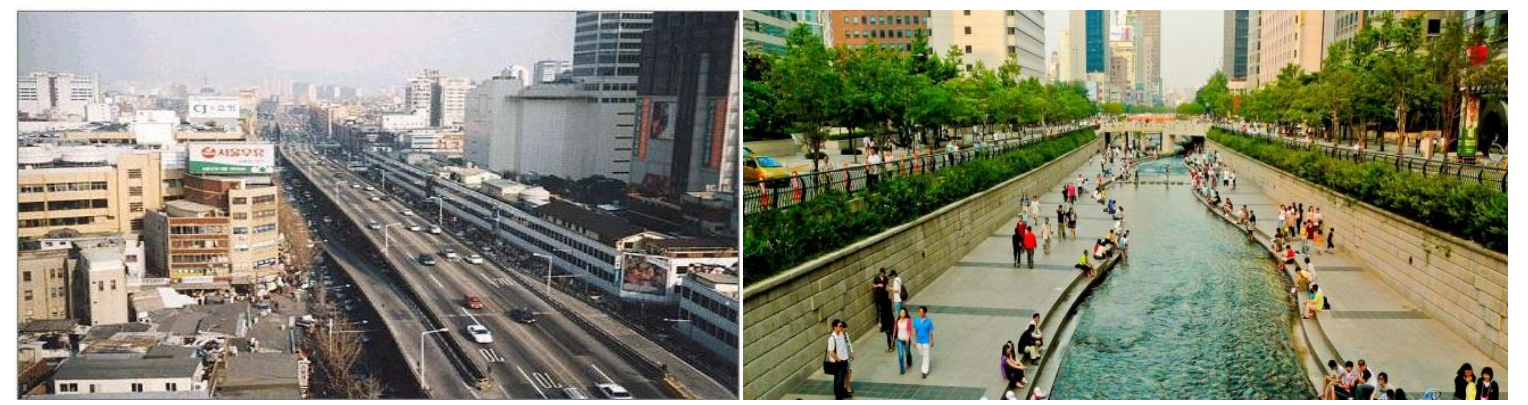

Fonte: http://www.superbac.com.br/a-despoluicao-de-rios-urbanos-e-realmente-possivel/. Acesso: Ago., 2017.

É uma tendência velhos centros industriais se renovarem ou áreas abandonadas e vazias se reconverterem em bairros criativos. As pessoas permanecem por mais tempo em locais confortáveis e em ambiente visualmente agradável. Espaços públicos de qualidade chamam pessoas, mais ruas chamam mais tráfego (JAN GEHL, 2013). Exemplos da literatura e projetos executados como o da figura (4) de renovação urbana, requalificam o espaço público ao retirar vias e elevados integrando rios a metas ecológicas, onde pessoas interagem ao invés de veículos.

10. Parceria e cooperação: nos ecossistemas naturais, os intercâmbios cíclicos de energia e recursos são sustentados por cooperação generalizada. $\mathrm{Na}$ sociedade humana, quando uma parceria se processa, cada parceiro passa a entender melhor as necessidades dos outros. A economia enfatiza a competição, a expansão e a dominação; e a ecologia enfatiza a cooperação, a conservação e a parceria (CAPRA, 2006b). A tendência é formar associações para cooperar, desenvolver a democracia e o poder pessoal, como fazem as ecovilas. A descentralização e as parcerias incentivam a gestão comunitária nas suas diversas formas com base no direito à cidadania. A Rede Global de Ecovilas é exemplo de parceria que reúne 15 mil ecovilas no mundo, para cooperar, através da informação (GEN, 2017).

\section{CONCLUSÃO}


A abordagem ecossistêmica entende necessária a interdependência do ser humano e da cidade com a natureza sob a probabilidade de colocar a própria sobrevivência em risco. Entende possível transformar o ambiente sem impactar, através do ecodesign dos sistemas de apoio, da arquitetura e urbanismo passivos, do reconhecimento dos valores próprios da natureza, no conjunto de relações complexas que atuam no ecossistema urbano: a natureza, a sociedade, a cultura e a economia.

$\mathrm{O}$ artigo demonstra que o planejamento e a gestão aos moldes ecossistêmicos podem fornecer a orientação na transformação de processos humanos com soluções arquitetônicas e urbanismo responsável com maior eficiência em relação ao alimento, água e energia do que existe nas cidades contemporâneas.

Por essa visão entende-se que é fundamental repensar o lugar de viver de maneira a remodelar os bairros da cidade aos moldes do funcionamento da natureza a fim de melhorar a saúde pública, diminuir custos sociais, econômicos e ecológicos e gerar empregos. Desta forma a transição para a sustentabilidade requer renovar da cidade como um todo, com ações de baixo custo econômico e ambiental e atitudes democráticas. Para isso será necessário capacitar pessoas às técnicas amenas, buscando outros métodos.

Já existe um movimento de milhares de pessoas, ao redor do planeta, que cultua soluções viáveis para a erradicação da pobreza e da degradação do meio ambiente. As ecovilas são comunidades ecossistêmicas que demonstram essas práticas cotidianas, entre outros exemplos pontuais e fragmentados.

Essa é uma mudança de paradigma. Por ser profunda e revolucionária, porquanto necessária é difícil, pois é compromisso coletivo e desafia o pensamento tradicional. Pressupõe primeiro a percepção da necessidade de mudança de hábitos e atitudes. Por isso, o trabalho induz ao empoderamento das pessoas, agentes fundamentais para possibilitar essa transição. Muito embora para que compreendam e se engajem sejam necessários os meios disponibilizados através de governantes, entidades e empresas com políticas públicas e o próprio planejamento. A percepção e conscientização da população e visão dos gestores são testemunho para repensar a cidade como um todo. Enquanto isso não acontece, crescem silenciosos os movimentos de mudança, como essa nossa proposta.

\section{REFERÊNCIAS}

AVALIAÇÃO Ecossistêmica do Milênio - AM (2001-2005). Disponível em: <http://www.mma.gov.br/estruturas/conabio/_arquivos/Rodrigo\%20Victor.pdf>. Acesso em: 10 ago. 2017. 
BERRY, W. The whole horse. In: The New Agrarianism: Land, Culture, and the Community of Life. Org. E. Freyfogle. Washington, DC: Island Press. 2001 (p.63-79).

CAPRA, Fridjof. O ponto de mutação: a ciência, a sociedade e a cultura emergente, Cultrix, São Paulo: 2006a.

$2006 \mathrm{~b}$.

A Teia da Vida: uma nova compreensão dos sistemas vivos. São Paulo: Cultrix,

DE OLIVEIRA, I. R.; MILIOLI, G. Sustentabilidade urbana e ecossistema: relações entre a sociedade, o desenvolvimento e o meio ambiente nos municípios. Curitiba: Juruá, 2014.

FRANCO, Maria de Assunção Ribeiro. Desenho ambiental: uma introdução à arquitetura da paisagem com o paradigma ecológico. 2. ed. São Paulo: Annablume; Fapesp, 2008.

GEN - Global Ecovillage Network. Disponível em: <https://ecovillage.org/acesso>. Acesso em: 15 ago. 2017.

GIBSON R, Alexander D.; TOMALTY R. Putting Cities in Their Place. In: Mark, R. (Ed.).

Eco City Dimensions: healty communities, healty planet. Canadá: New Society Publishers, 1997. p. 25-39.

GEHL, Jan. Cidades para pessoas. São Paulo: Perspectiva, 2013.

GIRARDET, H. Regenerative Cities. World Future Council, Hamburgo, 2010. Diponível em: <http://www.worldfuturecouncil.org/wp-

content/uploads/2016/01/WFC_2010_Regenerative_Cities.pdf>. Acesso em: 15 ago. 2017.

HERZOG, Cecília P. Cidades para todos: (re) aprendendo a conviver com a natureza. $1^{\mathrm{a}} \mathrm{ed}$.

Rio de Janeiro: Muad X: Inverde, 2013.

LEFF, Edgar. Discursos sustentáveis. São Paulo: Cortez, 2010.

MOLLISON B; Slay R. Introdução à permacultura. 2. ed. Austrália: A Tagari Publication, 1994.

MORIN, Edgar. Sociologia: a sociologia do microssocial ao macroplanetário. Portugal:

Europa-América, 1984

Ciência com consciência, Rio de Janeiro: Bertrand Brasil, 2001.

O método I: a natureza da natureza. Porto Alegre: Sulina, 2003.

MUCELIN, Carlos Alberto; BELLINI, Marta. O ecossistema urbano, percepção e determinados impactos ambientais. Revista Inovação e Tecnologia, Universidade Tecnológica Federal do Paraná, Campus Medianeira, v. 1, n. 1, 2010. Disponível em: <https://periodicos.utfpr.edu.br/recit/article/view/22/2643>. Acesso em: 15 ago. 2017. NEWMAN, Peter. Greening the city: the ecological and human dimensions of the city can be part of town planning. In: ROSELAND, Mark (Org.). Canadá. Eco - City Dimensions. New Society Publishers. 1997.

NEWMAN, P.; JENNINGS, I. Ecocities as sustainable ecosystems: principles and practices. Washington: Island Press, 2009.

ODUM, P. Fundamentos de ecologia. Lisboa: Fundação Calouste Gulbenkian, 2004.

PESCI, Ruben. Um novo humanismo e o Planejamento Ambiental. In: MENEGAT, Rualdo;

ALMEIDA, Gerson (Orgs.). Desenvolvimento sustentável e gestão ambiental nas cidades: estratégias a partir de Porto Alegre. Porto Alegre: editora UFRGS,2004. 422p.

ONU-BR. Relatório sobre cidades latino-americanas. ONU-HABITAT 2012. Disponível em: https://nacoesunidas.org/cidades-al-caribe-2012/Acesso: 17/07/2018 12:35h

PILLET, Gonzague. Economia ecológica: introdução à economia do ambiente e recursos naturais. Lisboa: Divisão editorial: Instituto Piaget, 1993.

REGISTER, Richard. Ecocities: rebuilding cities in balance with nature $-1^{\mathrm{a} e d}$. Canadá: new society publishers, 2006.

ROCHA, Paula Raquel da; VENDRAMINI, Jorge; BRUNA, Gilda Collet; MARQUES, Juliana Di Cesare Margini. Fragilidade ambiental das áreas urbanas: o metabolismo das 
cidades. Revista Vitruvios, ano 5, abr. 2005. Disponível em:

<http://www.vitruvius.com.br/revistas/read/arquitextos/05.059/472>. Acesso em 10 ago.

2017.

ROGERS, R. Cidades para um pequeno planeta. Barcelona: Gustavo Gilli SA, 2001.

RUEDA, S. Modelos de ciudad: indicadores básicos. Quaderns d'arquitectura i urbanisme, Barcelona, p. 25-32, 2000.

UNESCO Programa MaB - Man and Biosphere/UNESCO, 2001. Disponível em:

<http://www.rbma.org.br/mab/unesco_01_oprograma.asp>. Acesso em: 15 ago. 2017. 